\title{
Multi-response optimization of magnetic field assisted EDM through desirability function using response surface methodology
}

https://doi.org/10.1515/jmbm-2020-0003

Received Nov 25, 2019; accepted Feb 17, 2020

\begin{abstract}
Magnetic field assisted electrical discharge machining (MFAEDM) is the modification of in conventional EDM process by use of magnetic field on EN-31. This article explain the application of response surface methodology to analyzes the effect of various process parameters such as Ton, Toff and Ip on performance measures such as material removal rate (MRR), electrode wear rate (EWR) and overcut (OC). Analysis of variance was used to check the adequacy of response surface model and significance of process parameters on performance measures. Multi-objective desirability function has been applied to obtain the optimal process parameter settings. Thereafter, machined surface of EN-31 characterized through SEM and EDX. The novelty of this paper is to improve the strategies for flushing the debris which remain clogged in standard EDM in-between machining gap that will interrupts the regular discharge conditions and reduces cutting rate as well as deteriorate the surface characteristics.
\end{abstract}

Keywords: Magnetic field assisted electrical discharge machining (MFAEDM), material removal rate, electrode wear rate, overcut, material transfer mechanism, surface morphology, EDX

\section{Introduction}

In previous years, several researchers focused their interest in modification of standard EDM with different hybrid techniques like powder mixed, electro discharge chemical machining, electro discharge grinding, electro-discharge milling and wire cut EDM. In standard EDM we have ob-

\footnotetext{
*Corresponding Author: Anish Kumar: Department of Mechanical Engineering, M.M Deemed to Be University, Mullana, Ambala-133207, India; Email: anish_kaushik@rediffmail.com

Renu Sharma: Department of Physics, M.M Deemed to Be University, Mullana, Ambala-133207, India; Email: renuailesh@gmail.com
}

served the low MRR and surface quality. The standard EDM is known for tool and die making machine in which a series of discharges occurs having temperature in the range of $10000^{\circ} \mathrm{C}$ to $12,000^{\circ} \mathrm{C}$ between tool and work-piece. The tool and workpiece are immersed in dielectric kerosene and machined debris also washed away by dielectric [1]. There is no physical contact between tool and work piece which may produce no mechanical cutting forces, stresses, chatter and vibration problems, as it is well-known in conventional machining [2]. In conventional EDM enormous amount of debris clogged in the machining gap which results in low machining efficiency and surface roughness. Several authors utilized their hard work on magnetic force intensity applications to encourage the manufacturing technique and their effects of magnetic force process were confirmed from experimental findings. Makenzi et al. [3] was perceived that the surface roughness of mild steel improved with magnetic force assisted EDM. Yan et al. [4] performed to develop the quality of EDM surface through magnetic abrasive finishing process. Singh and Shan [5] applied the magnetic field around the work material in abrasive flow machining process and results showed that the surface integrities improved of both internal and external components. Cetin et al. [6] proposed a debris segregation model to assess and simulate the debris attentiveness in the machining zone area. Kremer et al. [7] developed the hybrid EDM assisted with ultrasonic vibration to improve the material removal rate. Lin et al. [8] studied the machining features of Ti-6Al-4V alloy by hybrid setup of EDM with USM. The experimental results indicated to reduce the recast layer thickness and also increase the machining efficiency. Lin and Lee [9] experimental investigation of machining parameters and also optimize the material removal rate, electrode wear rate and surface roughness through Taguchi and grey relation analysis of magneticforce-assisted EDM. Cao et al. [10] perceived that magneticforce-assisted EDM also finds the application for machining of non-ferromagnetic materials. The MRR of magneticforce-assisted EDM increases rapidly with the discharge current and pulse duration. Bhattacharya et al. [11] found

Ә Open Access. (C) 2020 A. Kumar and R. Sharma, published by De Gruyter. 
that with effective utilization of external magnetic field enhanced the material removal rate by expelling material from work piece inter-zone. Joshi et al. [12] observed that magnetic field develops the higher ionization and plasma confinement in dry EDM which was performed in pulsating magnetic field. Chattopadhyay et al. [13] investigated on reverse polarity of magnetic field that influences the rotary EDM parameters that affecting the surface roughness. Wang et al. [14] exposed the magnetic abrasive finishing for inner surface finishing of tubing. Wang et al. [15] exposed the comparative analysis of dielectric for EDM of titanium alloy. They achieved the highest material removal rate, a low electrode wear rate, fewer cracks, and better surface roughness in distilled water as compared to kerosene oil. Teimouri et al. [16] studied the hybrid rotary tool EDM assisted with magnetic field achieved low tool wear rate and overcut. Payal et al. [17] investigated the EDM surfaces of EN-31 tool steel. They found that for high discharge current, copper electrodes show highest MRR. Kumar et al. [18, 19] studied and optimize WEDM machining parameters and surface integrity by using response surface methodology. Lin et al. [20] investigated the magnetic force assisted EDM machining parameters and obtain the best optimal solution for output responses through Taguchi method. Peruri and Chaganti [21] review the magnetic assisted machining processes and their application in various fields.

Most of the work was explored to utilize the magnetic fields by single factor and performance measure variation and there is less work was reported on multi objective optimization using response surface methodology.

Based on the literature, novelty of the research work explores the paybacks of magnetic field assisted EDM (MFAEDM) were determined. Moreover, the essential EDM parameters such as Ton, Toff and Ip were varied to explore their effects on MRR, Electrode wear Rate (EWR) and Overcut (OC). The RSM based box-behnken design has been utilized to set level and their ranges to explore the above said performance characteristics. Analysis of variance has been utilized to validate the significance of process parameters and developed the empirical model for prediction of performance measures. Multi-objective desirability approach was carried out to optimize the machining parameters. Thereafter, surface characteristics were analyzed through morphology of machined samples by scanning electron microscope and EDX. The main objectives of applying a magnetic field involve:

1. To improve the strategies for flushing the debris which remain clogged in the inter-electrode gap that will interrupts the regular discharge conditions and reduces metal removal rate as well as deteriorate the surface roughness.

2. The machining gap area creates the magnetic field to sweep away the suspended debris when magnets were attached to standard EDM.

3. To get deeper and more accurate sparking plasma channel.

\section{Experimental details}

In this investigation, the experiments were conducted on a 4-Axis numerical control EDM manufactured by Electronica India Ltd, Pune hybrid with magnetic field assistance of permanent magnets set-up as shown in Figure 1(a) and 1(b). The chemical arrangement of work material (EN31) is taken as follows (wt. \%): $\mathrm{C}=0.96, \mathrm{Si}=0.226, \mathrm{Mn}=0.410$, $\mathrm{Ph}=0.015, \mathrm{Fe}=96.96, \mathrm{Cr}=1.22, \mathrm{~S}=0.024, \mathrm{Mo}=0.019, \mathrm{Ni}=0.068$ and $\mathrm{V}=0.013$. The rectangular form material having dimensions $100 \mathrm{~mm} \times 50 \mathrm{~mm} \times 3 \mathrm{~mm}$ was utilized for machining. Kerosene oil is taken as the dielectric. A cylindrical copper having $\varnothing 5 \mathrm{~mm}$ with $99.9 \%$ purity was used as the electrode. A neodymium magnet with a magnetic field intensity of 0.3Tesla was used. To obtain better MRR positive polarity was chosen. The parameters which are kept fixed during experimentation as shown in Table 1. The optimal parametric combinations were predicted based on desirability approach and conformation tests were also performed according to design of experiment. The machined holes are systematically polished, cleaned and etched with solution of acetone, $2 \mathrm{ml}$ of $\mathrm{HF}$ acid (30\%)+ $5 \mathrm{ml}$ of conc. of nitric acid with addition of deionized water. The investigation was further extended to examine the surface morphology in form of craters, cracks and recast layer.

Table 1: EDM fixed parameters

\begin{tabular}{ccc}
\hline Machining Parameters & Units & $\begin{array}{c}\text { Fixed operating } \\
\text { conditions }\end{array}$ \\
\hline Work-piece & - & EN31 \\
Plates size & $\mathrm{mm}$ & $100 \times 50 \times 3$ \\
Tool electrode & - & Copper \\
Work-piece Polarity & - & Positive \\
Electrode Polarity & - & Negative \\
Dielectric Fluid & - & Kerosene \\
Magnetic field & Tesla & $0.3 T$ \\
Intensity & & \\
\hline
\end{tabular}




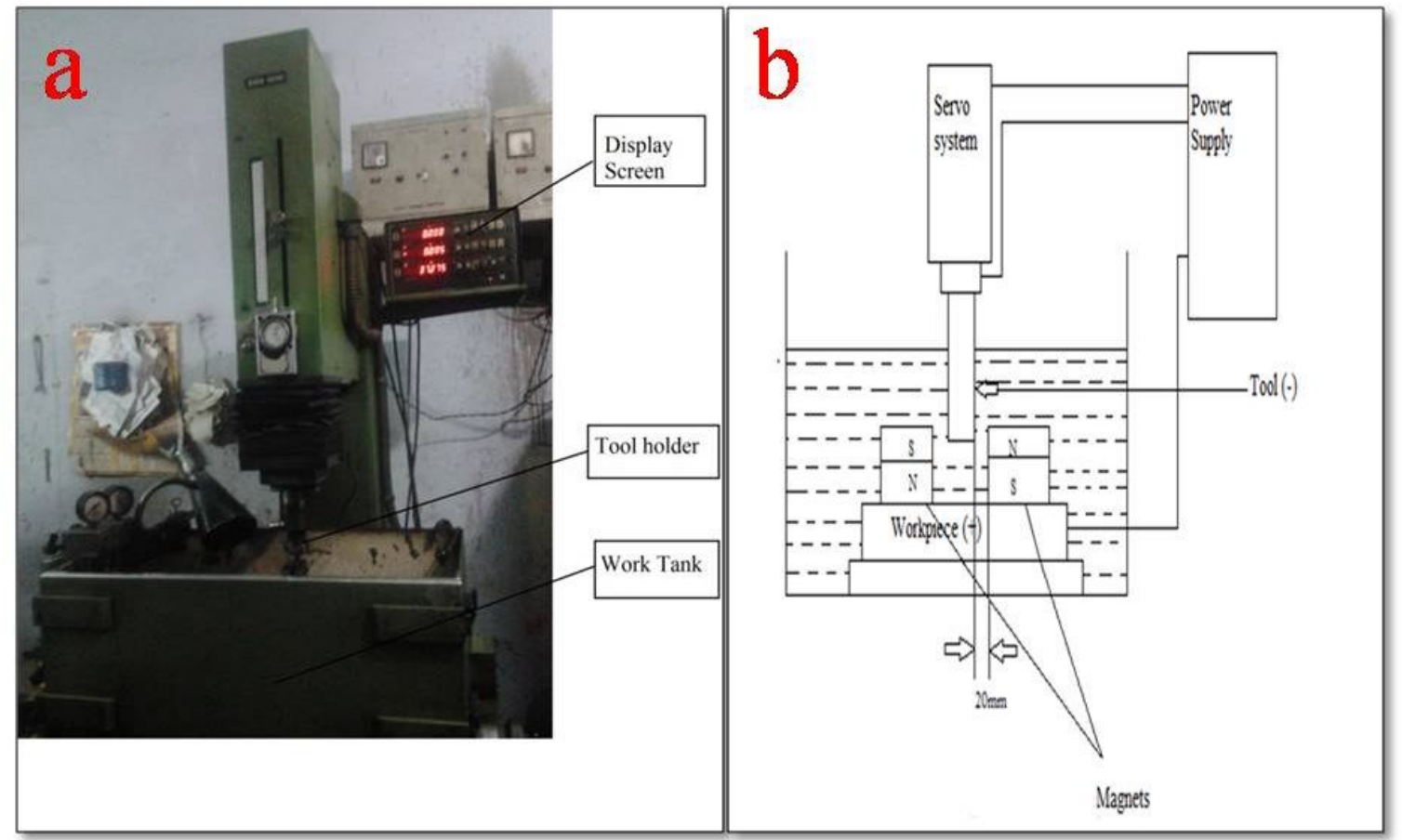

Figure 1: (a) Die sink EDM set-up; (b) Schematic diagram of magnetic Force assisted EDM

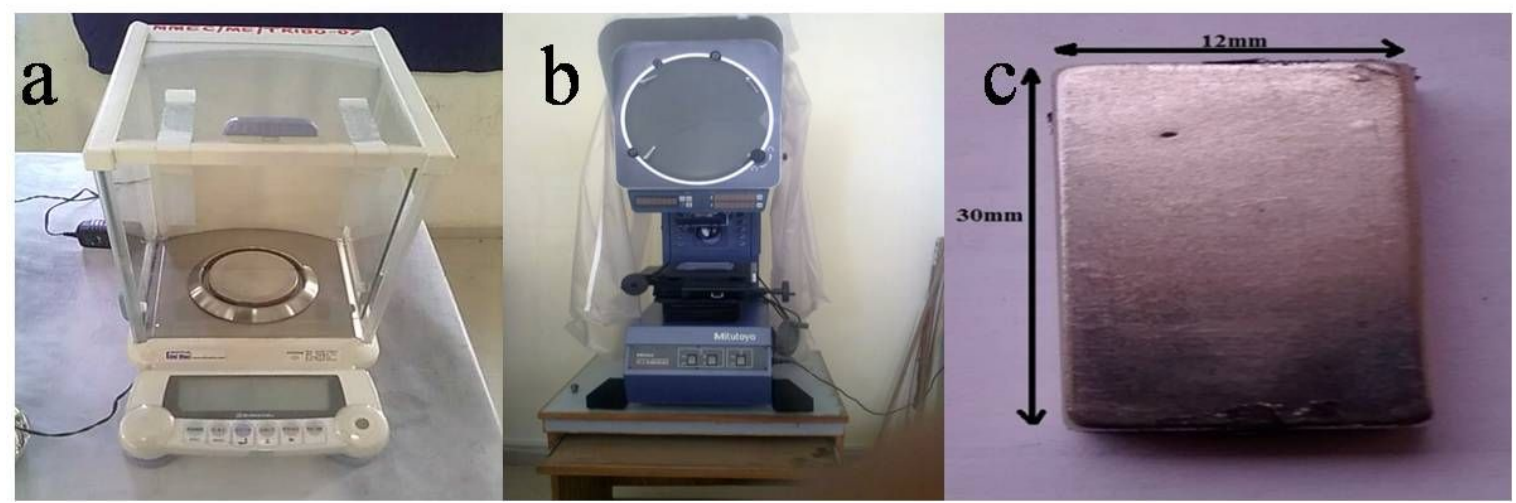

Figure 2: (a) Precision weight balance; (b) Profile projector; (c) Neodymium magnet

\section{Experimental procedure and test equipment}

Detailed procedure of conducting the experiments and recording the data as follows:

- Positive electrode polarity was selected while conducting the experiments. An initial weight of electrode and work piece is measured with Shimadzu make balance with model no. AUX 220 as shown in Figure 2 (a).
- Magnets are located at a distance $20 \mathrm{~mm}$ from the work-piece in machining area as shown in Figure 1 (b) and 2(c).

- Set the parameters of the according to design of experiment.

- Cutting time for conduct of each experiment is noted by a stop watch.

- The MRR of work-piece material is calculated by following formula:

$$
M R R=\frac{I_{w}-F_{w}}{M_{t}}
$$


Table 2: Parameters and their levels of experimental design

\begin{tabular}{|c|c|c|c|c|c|c|c|}
\hline S.No. & Symbols & $\begin{array}{c}\text { Input } \\
\text { parameters }\end{array}$ & $\operatorname{Low}(-)$ & $\begin{array}{c}\text { Parameters Level } \\
\text { Mediumm(0) }\end{array}$ & High(+) & Units & Definition of parameters \\
\hline 1. & $\mathrm{~T}_{\text {on }}$ & Pulse on Time & 10 & 30 & 50 & $\mu \mathrm{s}$ & $\begin{array}{c}\text { Due to increase of pulse on time the } \\
\text { discharge energy increases on } \\
\text { electrode. }\end{array}$ \\
\hline 2. & $\mathrm{~T}_{\text {off }}$ & Pulse off Time & 10 & 30 & 50 & $\mu \mathrm{s}$ & $\begin{array}{l}\text { At low pulse off time results in an } \\
\text { unstable process sand less time } \\
\text { available for de-ionization. As a } \\
\text { result, the cutting rate also } \\
\text { increases. }\end{array}$ \\
\hline 3. & Ip & Peak Current & 2 & 6 & 9 & $A$ & $\begin{array}{l}\text { Higher the peak current is the width } \\
\text { of peak wider and wider which } \\
\text { results larger size of craters on } \\
\text { machined surface. }\end{array}$ \\
\hline
\end{tabular}

Where, $I_{w}=$ Initial workpiece weight (g)

$F_{w}=$ Final weight of work-piece $(\mathrm{g})$

$C_{t}=$ Cutting time ( $\left.\mathrm{min}\right)$

- The EWR of electrode is calculated by following formula:

$$
E W R=\frac{I_{e}-F_{e}}{C_{t}}
$$

Where, $I_{e}=$ Initial electrode weight $(\mathrm{g})$

$F_{e}=$ Final electrode weight $(\mathrm{g})$

$C_{t}=$ Cutting time ( $\left.\mathrm{min}\right)$

- Diameter of the hole is measured on a profile projector manufactured by Mitutoyo with model no. PJA3000 as shown in Figure 2b.

- A total of 17 experiments were proposed as per design of box-behnken design.

\section{Experimental design}

For multi objective problems and a response surface methodology is the good combination of experimental and statistical method in engineering applications. Empirical modeling was developing to fit the model between the response $\mathrm{Y}$ and independent parameters $x_{1}, x_{2}, x_{3} \ldots \ldots$ $x_{n}$ [22]. In general, the relationship is as follows:

$$
Y=f\left(x_{1}, x_{2}, x_{3} \ldots \ldots x_{n}\right)
$$

Where

$Y=$ output of the response

$x_{n}=\mathrm{i}^{\text {th }}$ independent variables

In this research work there are three parameters were considered i.e. Ton, Toff and Ip. A polynomial quadratic model was considered which is given as follows: [23-26].

$$
Y=\beta_{0}+\sum_{i=1}^{k} \beta_{i} x_{i}+\sum_{i=1}^{k} \beta_{i i} x_{i}^{2}+\sum_{i<j} \beta_{i j} x_{i} x_{j}+\epsilon
$$

Where

$Y=$ Predicted Response

$x_{n}=\mathrm{i}^{\text {th }}$ control parameter, $\mathrm{i}=1,2, \ldots \ldots \mathrm{k}$

$\beta=$ regression coefficient

$\epsilon=$ chance error

$k=$ number of parameters

The main objective of study was to explore the effects of Ton, Toff and Ip on MRR, EWR and OC. Table 2 shows the level of process parameters at which experimentation is to be carried out. These levels have been decided after detailed review of past work and pilot experimentation.

\section{Results and discussion}

\subsection{Mathematical model and parametric effect on MRR}

The adequacy of model and their interaction effects of parameters for the response MRR as shown in ANOVA Table 4. The model $F$ value of 67.56 and $p$ values is less than 0.05 implies that model is significant at $95 \%$ of confidence interval. It was observed that the factors A (Ton) and C (Ip) have a most significant effect on MRR because of major percentage of contribution i.e. $53.42 \%$ and $25.04 \%$. The lack of fit $\mathrm{F}$ value of 1.07 implies that it is not significant compared to pure error. The determination of coefficient of "R-squared" 0.9886 and "Adj. R-squared” of 0.9473 which indicated that 
Table 3: Experimental design and results

\begin{tabular}{|c|c|c|c|c|c|c|}
\hline \multicolumn{4}{|c|}{ Factors } & \multicolumn{3}{|c|}{ Response variables } \\
\hline Run No. & Ton $(\mu s)$ & Toff $(\mu \mathrm{s})$ & Ip (A) & $\operatorname{MRR}\left(\mathrm{mm}^{3} / \mathrm{min}\right)$ & $\operatorname{EWR}\left(\mathrm{mm}^{3} / \mathrm{min}\right)$ & $\mathrm{OC}(\mathrm{mm})$ \\
\hline 1. & 30 & 30 & 6 & 14.66 & 0.26 & 0.33 \\
\hline 2. & 50 & 30 & 2 & 2.00 & 0.02 & 0.22 \\
\hline 3. & 30 & 10 & 2 & 3.39 & 0.06 & 0.11 \\
\hline 4. & 50 & 10 & 6 & 14.34 & 0.17 & 0.28 \\
\hline 5. & 10 & 30 & 2 & 1.73 & 0.01 & 0.16 \\
\hline 6. & 30 & 30 & 6 & 10.41 & 0.14 & 0.26 \\
\hline 7. & 50 & 30 & 9 & 8.10 & 0.11 & 0.32 \\
\hline 8. & 10 & 30 & 9 & 7.44 & 0.13 & 0.34 \\
\hline 9. & 30 & 30 & 6 & 8.58 & 0.13 & 0.33 \\
\hline 10. & 30 & 30 & 6 & 10.57 & 0.11 & 0.30 \\
\hline 11. & 10 & 50 & 6 & 6.40 & 0.13 & 0.31 \\
\hline 12. & 30 & 50 & 9 & 10.60 & 0.12 & 0.33 \\
\hline 13. & 30 & 10 & 9 & 8.53 & 0.22 & 0.24 \\
\hline 14. & 10 & 10 & 6 & 9.44 & 0.09 & 0.29 \\
\hline 15. & 30 & 50 & 2 & 1.88 & 0.02 & 0.33 \\
\hline 16. & 30 & 30 & 6 & 12.59 & 0.18 & 0.30 \\
\hline 17. & 50 & 50 & 6 & 8.96 & 0.15 & 0.26 \\
\hline
\end{tabular}

Legend: $\mathrm{T}_{\text {on }}$ - Pulse on time, $\mathrm{T}_{\text {off }}$ - Pulse off time, $\mathrm{I}_{p}$ - Peak current, MRR - Material removal rate, EWR- Electrode wear rate, OC- Overcut

Table 4: ANOVA for response surface quadratic model for MRR

\begin{tabular}{cccccccc}
\hline Source & SS & DOF & MS & F value & Prob $>\mathbf{F}$ & At95\%Cl & \%Contribution \\
\hline Model & 186.87 & 9 & 20.76 & 67.56 & $<0.0001$ & significant & \\
A & 100.45 & 1 & 100.45 & 326.85 & $<0.0001$ & significant & 53.42 \\
B & 8.61 & 1 & 8.61 & 28.02 & 0.0011 & significant & 4.45 \\
C & 47.10 & 1 & 47.10 & 153.26 & $<0.0001$ & significant & 25.04 \\
A $^{2}$ & 10.83 & 1 & 10.83 & 35.23 & 0.0006 & significant & 5.75 \\
C $^{2}$ & 12.19 & 1 & 12.19 & 39.16 & 0.0004 & significant & 6.48 \\
AB & 4.45 & 1 & 4.45 & 14.49 & 0.0067 & significant & 2.36 \\
AC & 2.91 & 1 & 2.91 & 9.47 & 0.0173 & significant & 1.54 \\
BC & 0.090 & 1 & 0.090 & 0.29 & 0.6052 & & \\
Lack of fit & 0.96 & 3 & 0.32 & 1.07 & 0.4569 & Not significant & \\
\hline$R^{2}=0.9886$ & & & & & &
\end{tabular}

$R^{2}=0.9886$

Adjusted $R^{2}=0.9740$

Predicated $R^{2}=0.9092$

Legend: CI- confidence interval, DOF-degree of freedom, MS- mean sum of squares, SS - Sum of squares.

predicted and experimental results had great perfect agreement. The empirical model equation for MRR is given by:

$$
\begin{aligned}
M R R & =+6.58209-0.20950 \times T_{\text {on }}-0.2056 \times T_{\text {off }} \\
& +1.9198 \times I_{p}+4.00875 E-003 \times T_{\text {on }}^{2}-0.13890 \\
& \times I_{p}^{2}+2.63750 E-003 \times T_{\text {on }} \times T_{\text {off }}+0.012186 \\
& \times T_{\text {on }} \times I_{p}-2.14286 E-003 \times T_{\text {off }} \times I_{p}
\end{aligned}
$$

It can be seen from the main effect plots as shown in Figure $3 a-3 c$ that the MRR increases significantly with effect of Ton. It means that the number of sparks in unit time increases which increases in discharge energy. MRR is directly proportional to discharge energy. As a result material removal rate becomes faster with increase in Ton. When Toff increase, the number of discharges with in given period of time decreases. The MRR increases with increase of Ip. When Ip is low, large portion of energy is use to vaporize the metal so that the MRR is less at low current [27, 28]. MRR increase with Ip because at high current discharge 

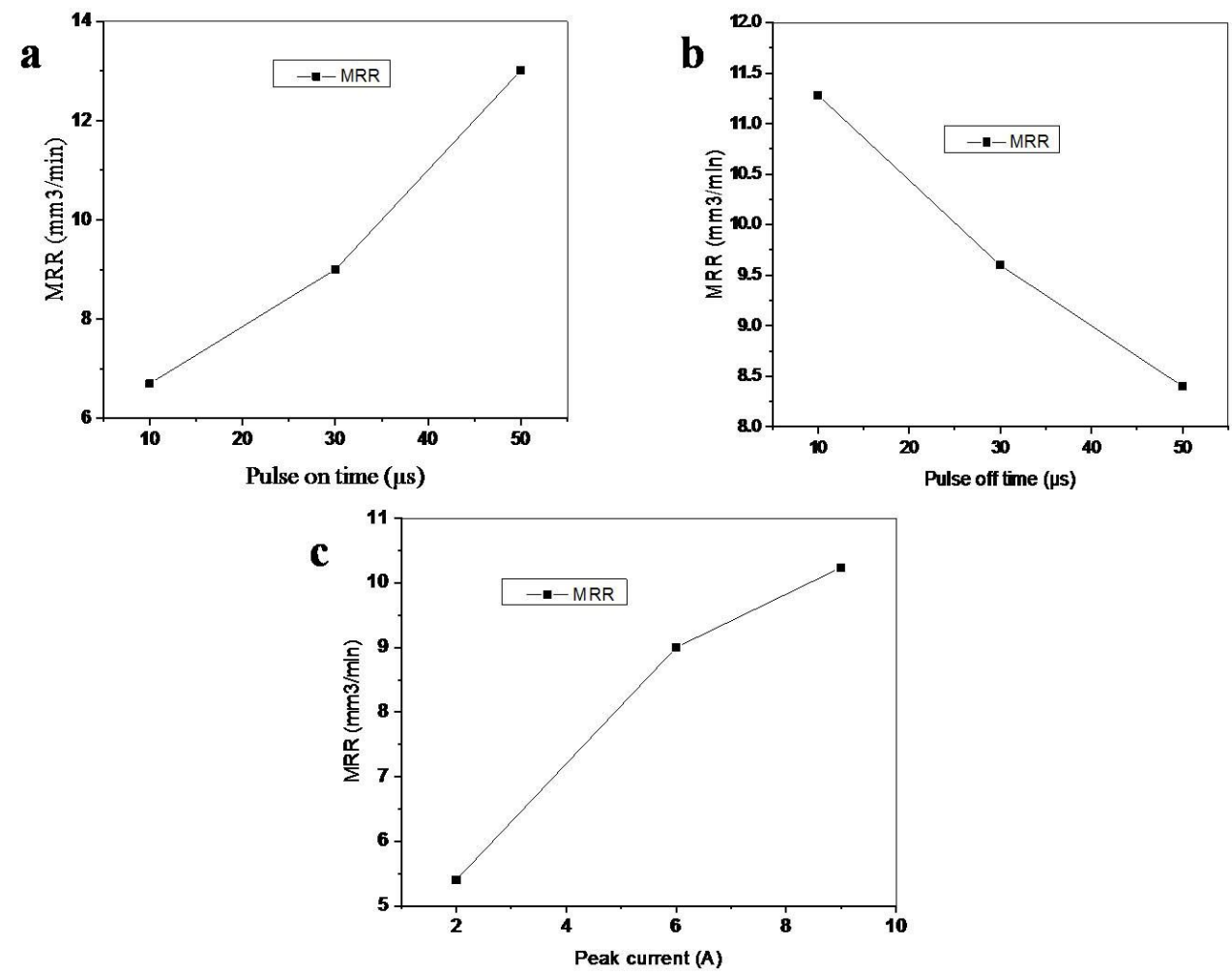

Figure 3: Main effect Plots for MRR (a) Ton Vs MRR; (b) Toff Vs MRR; (c) Ip Vs MRR
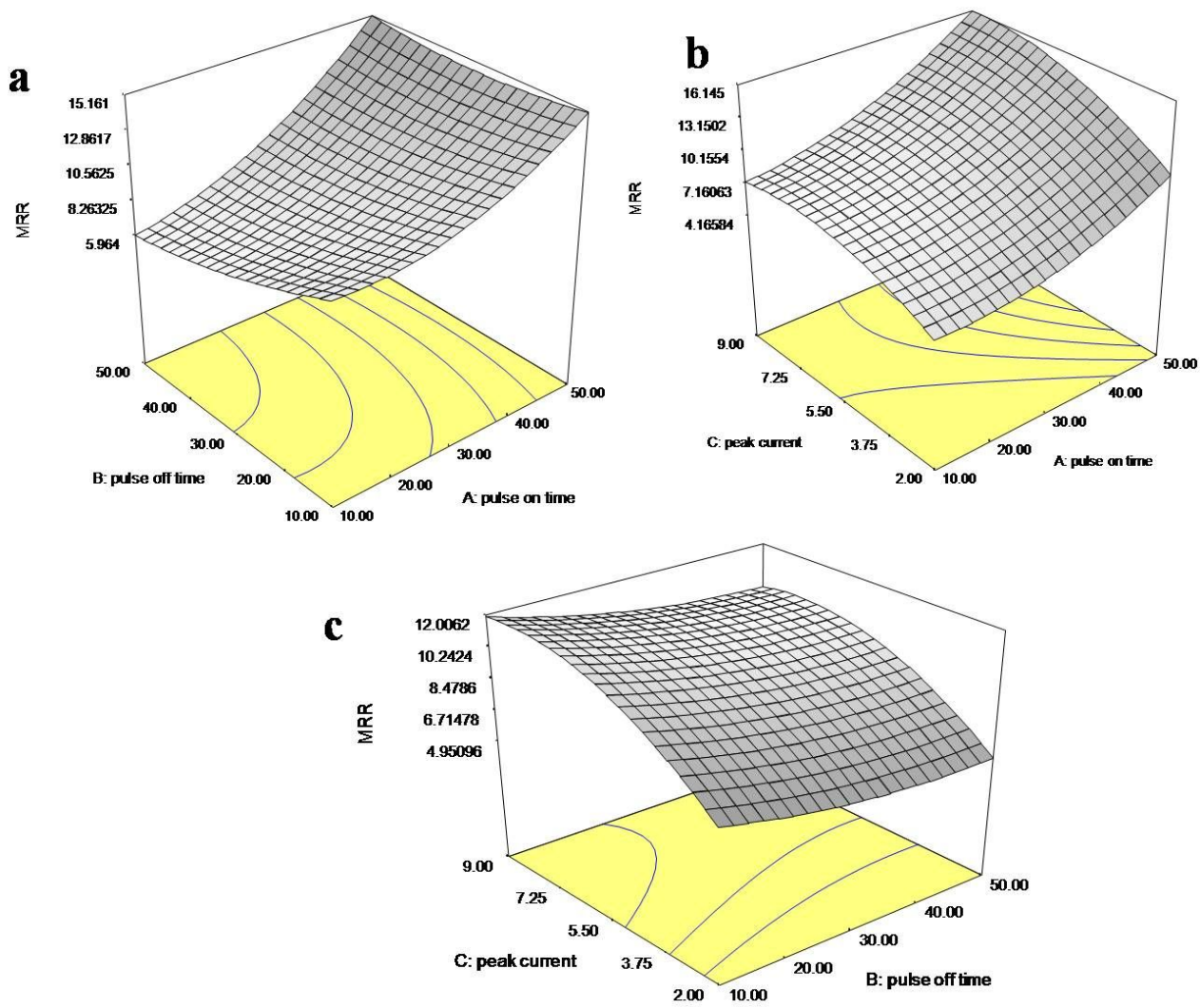

Figure 4: Interaction Plots for MRR (a) Ton Vs Toff; (b) Ton Vs Ip; (c) Toff Vs Ip 
Table 5: The ANOVA for response surface quadratic model for EWR

\begin{tabular}{cccccccc}
\hline Source & SS & DOF & MS & F value & Prob $>$ F & At95\%Cl & \%Contribution \\
\hline Model & 0.018 & 9 & 0.00198 & 35.52 & $<0.0001$ & Significant & \\
A & 0.00692 & 1 & 0.00692 & 124.4 & $<0.0001$ & Significant & 43.4 \\
B & 0.00186 & 1 & 0.00186 & 2.00 & 0.0007 & significant & 10.33 \\
C & 0.00396 & 1 & 0.00396 & 33.25 & $<0.0001$ & significant & 22.00 \\
A $^{2}$ & 0.00112 & 1 & 0.00112 & 70.78 & 0.029 & significant & 6.23 \\
AB & 0.00060 & 1 & 0.00060 & 20.05 & 0.0136 & significant & 3.35 \\
AC & 0.00275 & 1 & 0.00275 & 10.73 & 0.0002 & significant & 15.31 \\
BC & 0.00038 & 1 & 0.00038 & 49.26 & 0.0351 & significant & 2.11 \\
Lack of fit & 0.00031 & 3 & 0.00013 & 5.10 & 0.0748 & Non significant & \\
\hline $\mathrm{R}^{2}=0.9786$ & & & & & & \\
Adjusted $\mathrm{R}^{2}=0.9510$ & & & & & \\
Predicated $\mathrm{R}^{2}=0.7213$ & & & & & \\
Legend: CI- confidence interval, DOF- degree of freedom, MS - mean sum of squares, SS- Sum of squares.
\end{tabular}

energy is large. The interaction plots for the above said response as shown in Figure 4a-4c. It was observed that MRR increased from $1.73 \mathrm{~mm}^{3} / \mathrm{min}$ to $14.66 \mathrm{~mm}^{3} / \mathrm{min}$ with the increase Ton from $10 \mu$ s to $50 \mu$ s with simultaneous decrease of Toff from 50 to $10 \mu \mathrm{s}$. It was also observed MRR increasing from $1.73 \mathrm{~mm}^{3} / \mathrm{min}$ to $16.14 \mathrm{~mm}^{3} / \mathrm{min}$ with simultaneous increase of Ip and Ton. The same effect of MRR increased from $4.9 \mathrm{~mm}^{3} / \mathrm{min}$ to $12 \mathrm{~mm}^{3} / \mathrm{min}$. with simultaneous vary of Toff and Ip. It was observed that by simultaneous increasing of Ip and decreases of Toff the rate of discharge energy increases.

\subsection{Mathematical model and parametric effect on EWR}

By applying the multiple regression analysis on observed values, a predictive empirical relationship as presented in following equation that describe the correlation between response EWR and three parameters.

$$
\begin{aligned}
E W R & =+3.80714 E-003+5.06750 E-003 \times T_{\text {on }} \\
& -1.64857 E-003 \times T_{\text {off }}+0.016414 \times I_{P} \\
& -4.08125 E-005 \times T_{\text {on }}^{2}+3.06250 E-005 \times T_{\text {on }} \\
& \times T_{\text {off }}-3.75000 E-004 \times T_{\text {on }} \times I_{P} \\
& +1.39286 E-004 \times T_{\text {off }} \times I_{P}
\end{aligned}
$$

To describe the significance and importance of developed quadratic model was observed in Table 5. From these observations the factors $\mathrm{A}, \mathrm{B}, \mathrm{C}$ and three interaction terms $\mathrm{AB}, \mathrm{AC}$ and $\mathrm{BC}$ were found to be the significant for EWR.

The insignificant model terms are reduced by backward elimination method and improved the model. The model F-value of 35.52 suggests that model is significant and "lack of fit F value" of 5.40 implies that it is not significant compared to pure error. There is only a $0.01 \%$ chance that a "Model F-value" this large could occur due to noise. The "R-squared" value of 0.9786 and other adequacy measures is rreasonable agreement with the "Adj. R-squared" value of 0.9510. From Figures $5 a-5 c$ and 6a6c it can observed that EWR is affecting by Ton, Toff and Ip. It appeared from these figures that EWR varies from $0.015 \mathrm{~mm}^{3} / \mathrm{min}$ to $0.26 \mathrm{~mm}^{3} / \mathrm{min}$ with the increase Ton by10 $\mu$ s to $50 \mu$ s and with parallel decrease of Toff by 50 to $10 \mu$ s.

\subsection{Mathematical model and parametric effect on overcut (OC)}

Overcut (OC) of the machined hole was measured by deducting the diameter of the tool electrode $\left(D_{T E}\right)$ from the diameter of machined hole $\left(\mathrm{D}_{M H}\right)$ as given in follows:

$$
O C=D_{M H}-D_{T E}
$$

The profile of machined hole is not truely cylindrical but tappered because of debris movement and discharge occuring at the side surface in addition wear also occurs at the fornt end of the tool electrode [29]. From the ANOVA Table 6 the model $F$ value of 28.16 implied that the model is significant for overcut. In this case A, B, C, $\mathrm{C}^{2}$ and AC were the significant model terms. The "R-squared" value of 0.9356 and other adequacy measures is rreasonable agreement with the "Adj. R-squared" value of 0.9614. This model indicated that predicted and experimental results had great perfect agreement be used to navigate the empir- 

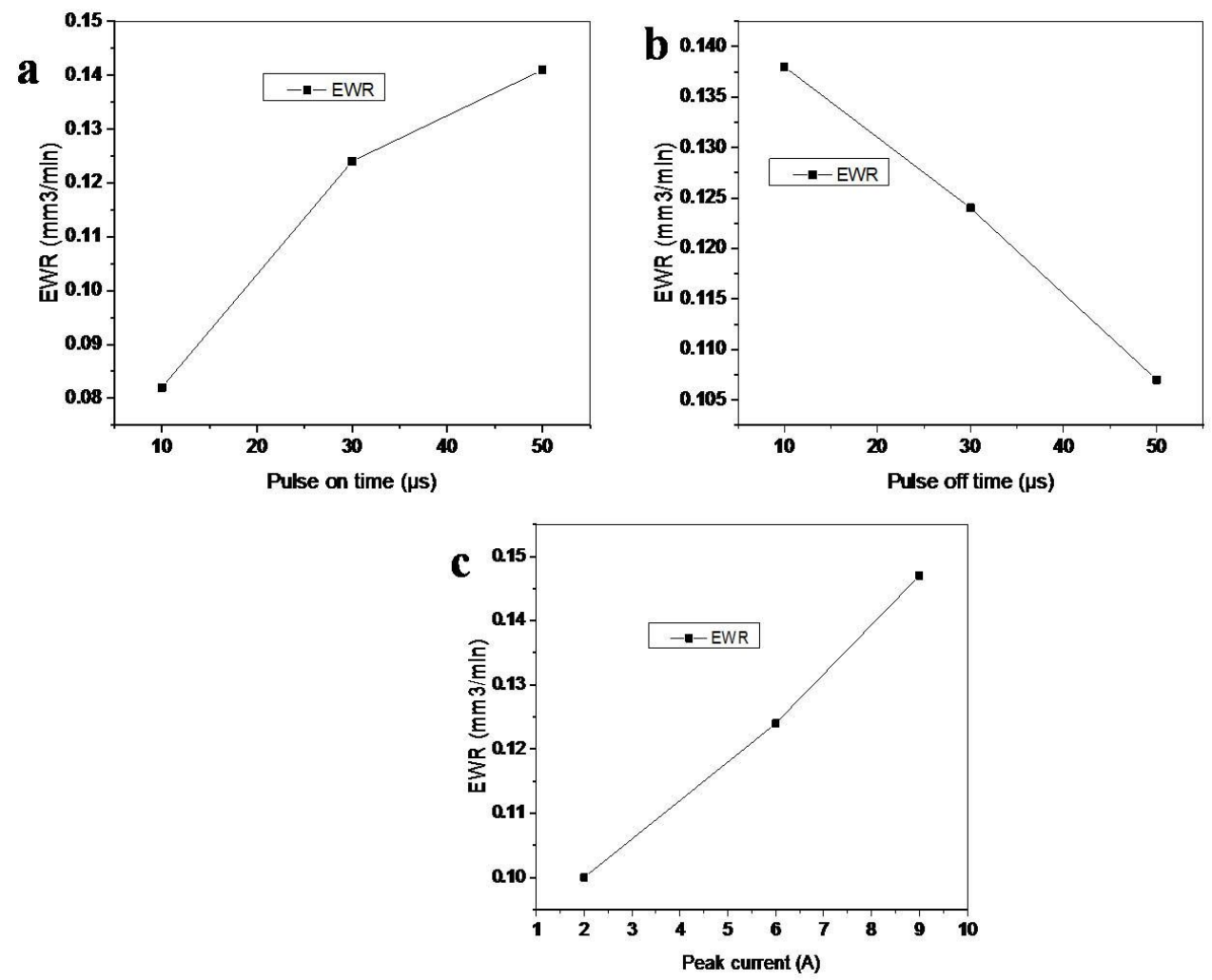

Figure 5: Main effect Plots for EWR (a) Ton Vs EWR; (b) Toff Vs EWR; (c) Ip Vs EWR

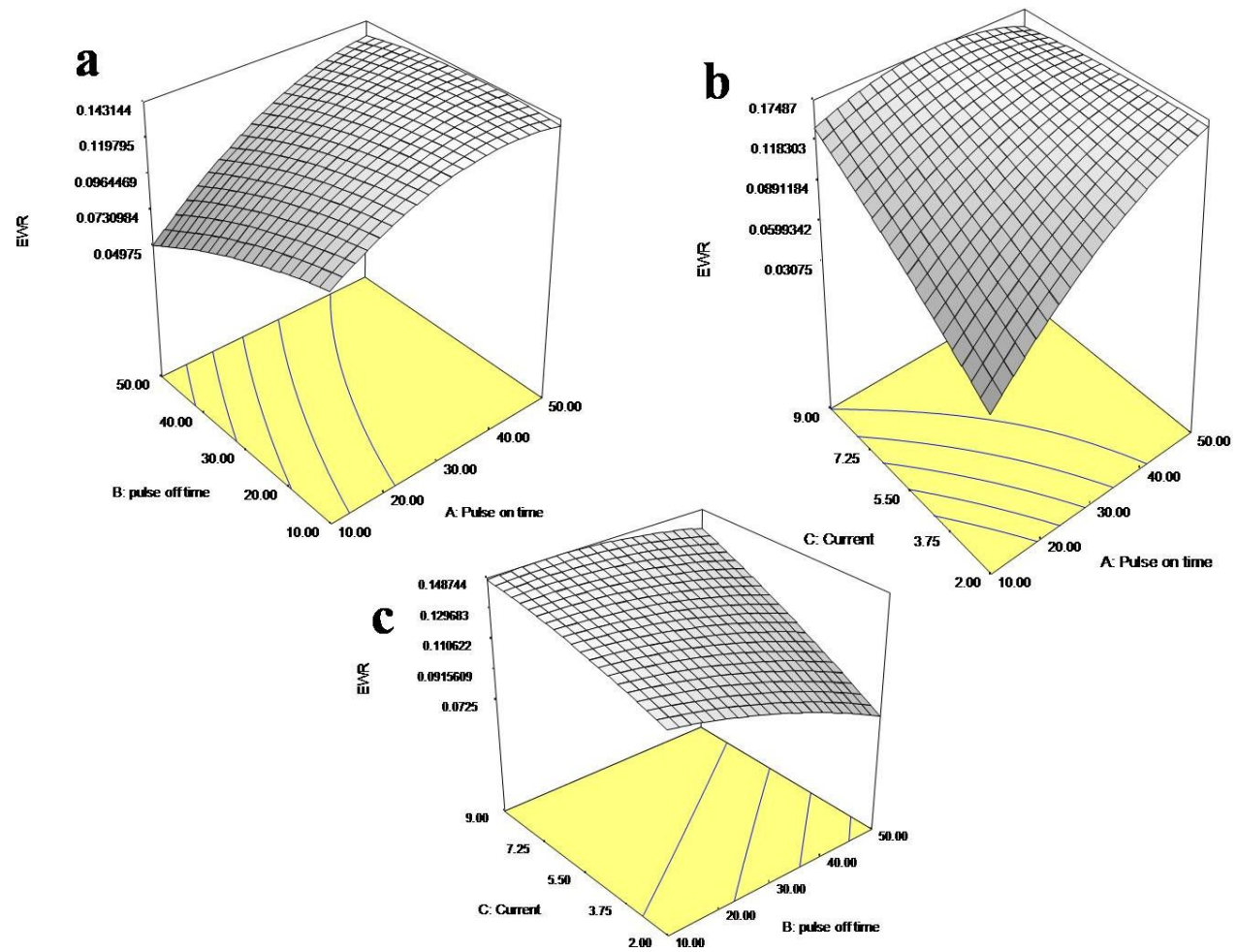

Figure 6: Interaction Plots for EWR (a) Ton Vs Toff; (b) Ton Vs Ip; (c) Toff Vs Ip 

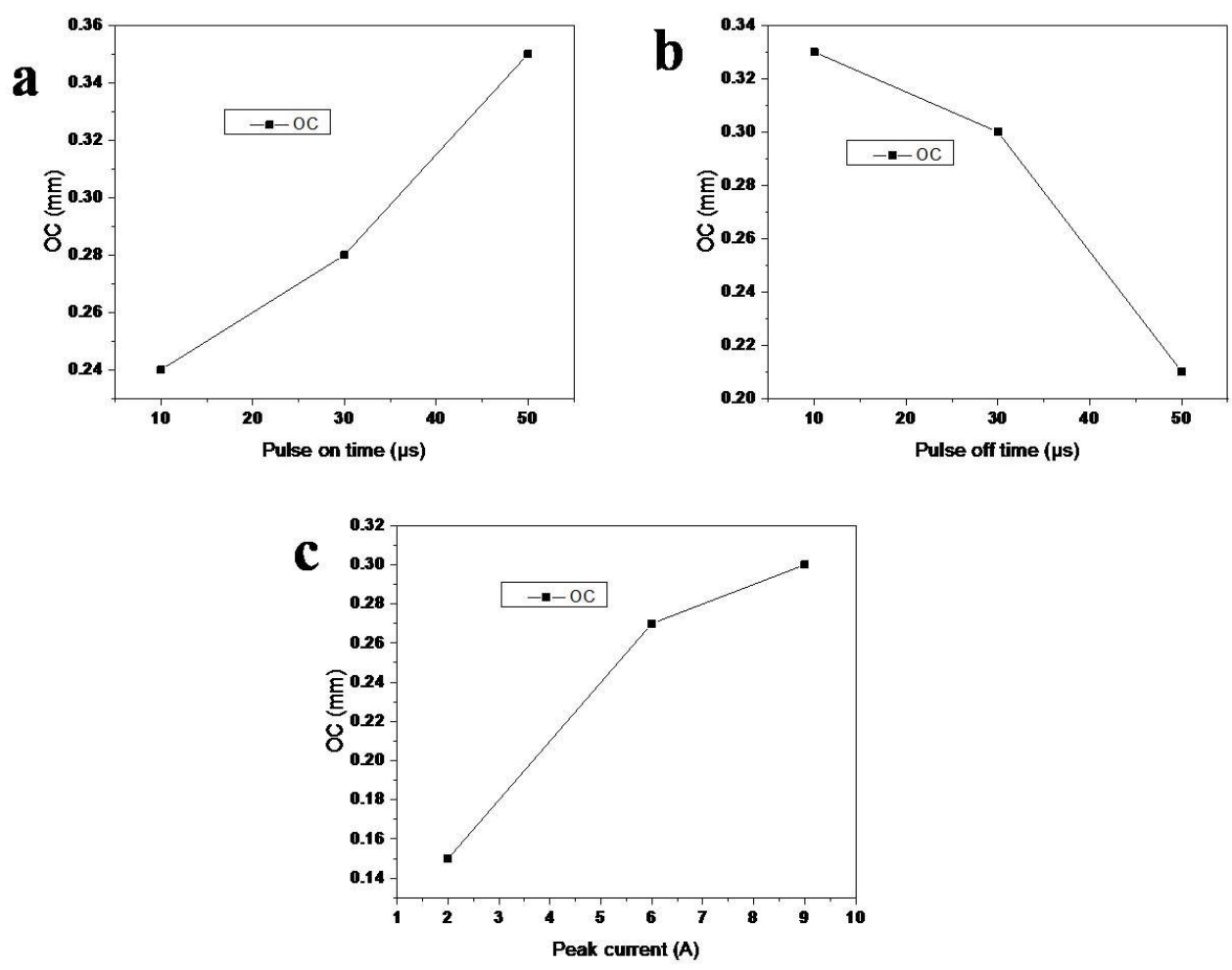

Figure 7: Main effect Plots for Overcut (a) Ton Vs OC; (b) Toff Vs OC; (c) Ip Vs OC

Table 6: ANOVA for response surface quadratic model for Overcut

\begin{tabular}{cccccccc}
\hline Source & SS & DOF & MS & F value & Prob $>\mathbf{F}$ & At95\%Cl & \%Contribution \\
\hline Model & 0.12 & 9 & 0.014 & 28.16 & $<0.0001$ & Significant & \\
A & 0.024 & 1 & 0.024 & 50.12 & 0.0002 & Significant & 20.16 \\
B & 0.029 & 1 & 0.029 & 59.64 & $<0.0001$ & Significant & 24.36 \\
C & 0.048 & 1 & 0.048 & 99.51 & $<0.0001$ & Significant & 40.33 \\
C & 0.015 & 1 & 0.015 & 31.65 & 0.0008 & Significant & 12.60 \\
AC & 0.0030 & 1 & 0.0030 & 6.26 & 0.0408 & Significant & 2.54 \\
Lack of fit & 0.0021 & 3 & 0.0007 & 2.19 & 0.2321 & Non Significant & \\
\hline
\end{tabular}

$\mathrm{R}^{2}=0.9356$

Adjusted $R^{2}=0.9614$

Predicated $R^{2}=0.7716$

Legend: CI- confidence interval, DOF- degree of freedom, MS- mean sum of squares, SS- Sum of squares.

ical relation for the OC was modeled as follows:

$$
\begin{aligned}
\text { Overcut }(O C) & =-0.076638+2.88571 E-003 \times T_{\text {on }} \quad(8) \\
& +1.00000 E-004 \times T_{\text {off }}+0.095531 \times I_{P} \\
& -4.91837 E-003 \times I_{P}^{2}-3.92857 E-004 \\
& \times T_{\text {on }} \times I_{P}
\end{aligned}
$$

From Figures $7 \mathrm{a}-7 \mathrm{c}$ and $8 \mathrm{a}-8 \mathrm{c}$ it can observed that overcut is affecting by Ton, Toff and Ip. It appeared from these figures that overcut varies from $0.16 \mathrm{~mm}$ to $0.38 \mathrm{~mm}$ with simultaneous increase of Ton and decrease of Toff. It was also observed overcut increasing from $0.077 \mathrm{~mm}$ to
$0.363 \mathrm{~mm}$ with simultaneous increase of Ip and Ton. It was observed that due to increase of Ip and Ton and low pulse off the overcut increases. Deeper and larger craters have been observed at workpiece profile. The debris makes the ridges and lumps due to high discharge energy as a result overcut increases. 


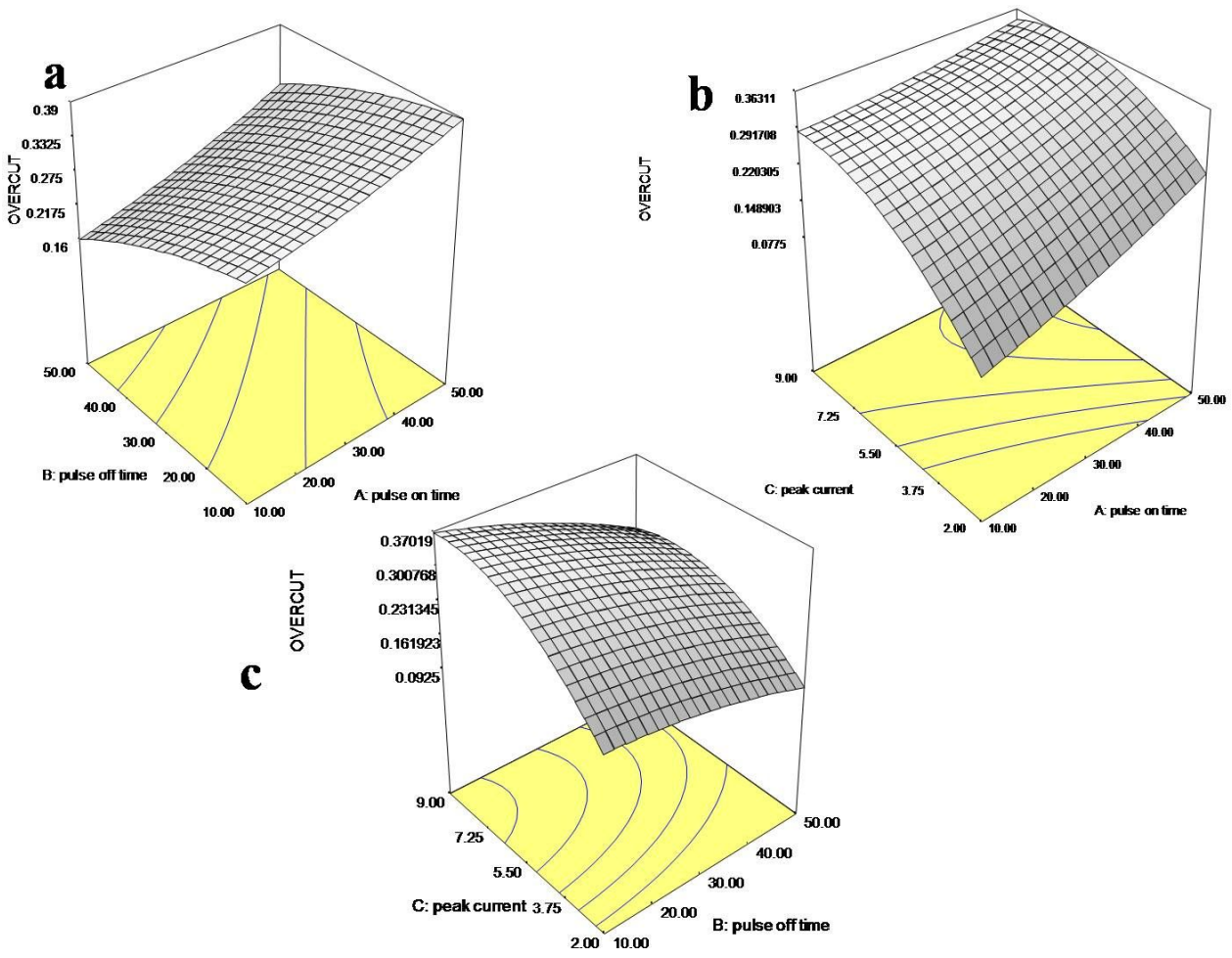

Figure 8: Interaction Plots for Overcut (a) Ton Vs Toff; (b) Ton Vs Ip; (c) Toff Vs Ip

Table 7: Material migration in magnetic field assisted EDM

\begin{tabular}{ccccccccc}
\hline Sample No. & \multicolumn{3}{c}{ Control Factors } & \multicolumn{4}{c}{ Material migration to machined samples (\%) } \\
& $\begin{array}{c}\text { Peak current } \\
(\mathbf{A})\end{array}$ & $\begin{array}{c}\text { Pulse on time } \\
(\boldsymbol{\mu} \mathbf{s})\end{array}$ & $\begin{array}{c}\text { Pulse off time } \\
(\boldsymbol{\mu} \mathbf{s})\end{array}$ & $\mathbf{C}$ & $\mathbf{0}$ & Al & Cr & Fe \\
\hline 1 & 6 & 30 & 30 & 51.57 & - & 0.99 & - & 47.44 \\
5 & 2 & 10 & 30 & 55.59 & 7.63 & 13.69 & - & 23.19 \\
7 & 9 & 50 & 30 & 66.70 & 18.18 & 1.40 & 0.48 & 13.24 \\
15 & 2 & 30 & 50 & 54.46 & 1.47 & 1.47 & 0.73 & 43.24 \\
\hline
\end{tabular}

Table 8: Multi Response Optimization through desirability function

\begin{tabular}{ccccccccc}
\hline S.No & Ton $(\boldsymbol{\mu s})$ & Toff $(\boldsymbol{\mu s})$ & Ip A & MRR $\mathbf{~ m}^{\mathbf{3}} / \mathbf{m i n}$ & EWR $\mathbf{~ m}^{\mathbf{3}} / \mathbf{m i n}$ & OC $\mathbf{~ m m}$ & Desirability & \\
\hline 1. & $\underline{10.00}$ & $\underline{10.00}$ & $\underline{3.18}$ & $\underline{8.26257}$ & $\underline{0.0776426}$ & $\underline{0.187511}$ & $\underline{0.563}$ & Selected \\
2. & 10.00 & 10.00 & 2.96 & 8.00717 & 0.0749302 & 0.174623 & 0.562 & \\
3. & 10.00 & 10.00 & 3.46 & 8.56604 & 0.0810366 & 0.203121 & 0.562 & \\
4. & 10.00 & 10.46 & 3.25 & 8.266166 & 0.0778832 & 0.190513 & 0.561 & \\
5. & 10.66 & 10.00 & 2.97 & 7.97396 & 0.0772984 & 0.176697 & 0.555 & \\
6. & 11.08 & 10.00 & 3.55 & 8.6059 & 0.0856173 & 0.210671 & 0.549 & \\
7. & 11.42 & 10.00 & 3.51 & 8.54028 & 0.0861661 & 0.208974 & 0.446 & \\
8. & 37.70 & 50.00 & 3.89 & 9.41468 & 0.110741 & 0.202916 & 0.417 & \\
9. & 36.04 & 50.00 & 4.03 & 9.13172 & 0.108261 & 0.20024 & 0.417 & \\
10. & 50.00 & 50.00 & 8.92 & 16.5946 & 0.135695 & 0.259337 & 0.359 & \\
11. & 50.00 & 50.00 & 8.62 & 16.5987 & 0.135733 & 0.266052 & 0.353 & \\
12. & 50.00 & 32.27 & 9.00 & 16.1374 & 0.134947 & 0.334371 & 0.300 & \\
\hline
\end{tabular}




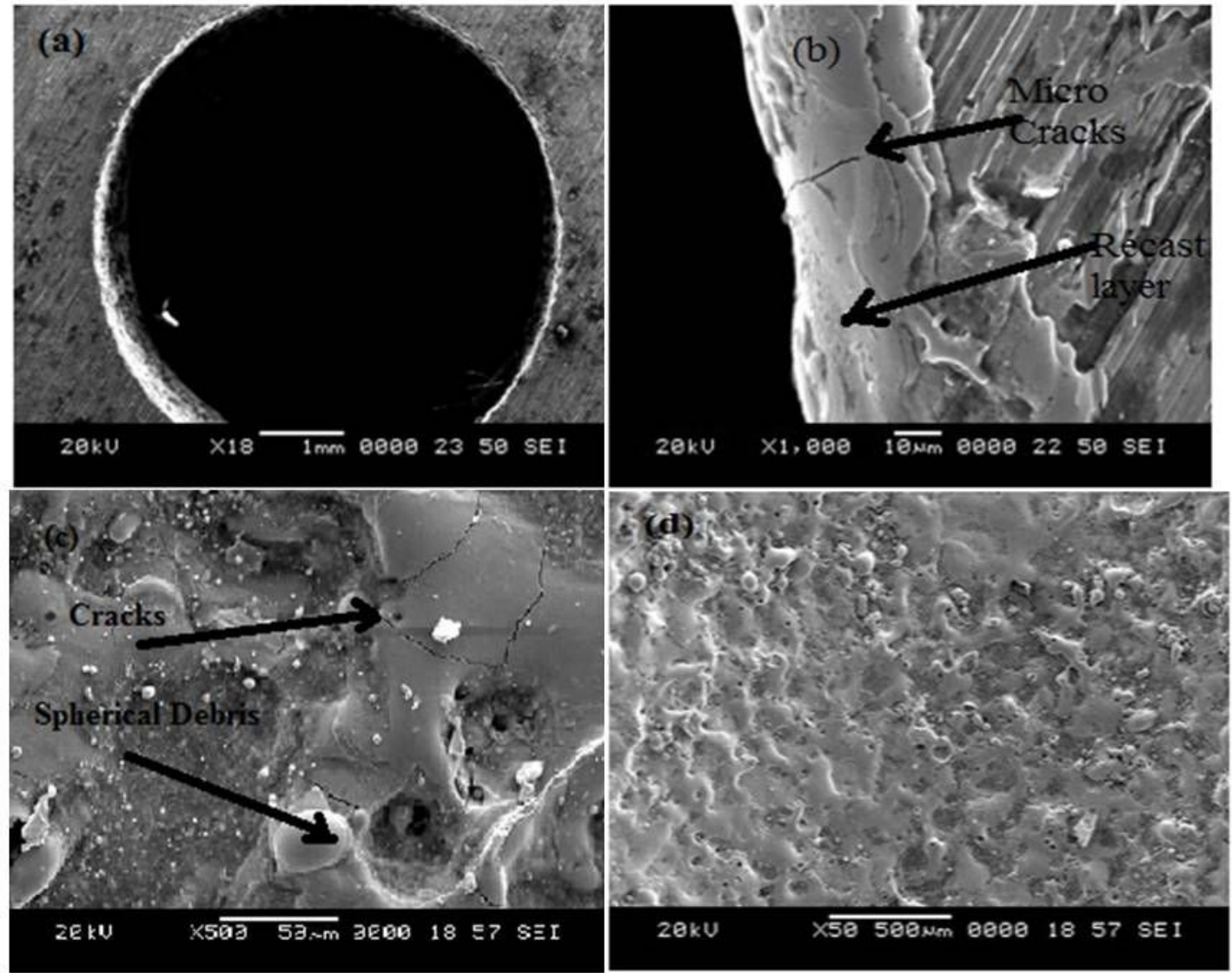

Figure 9: SEM micrograph: Exp No. 1 at; $\mathrm{T}_{o n}=30 \mu \mathrm{s} ; \mathrm{T}_{\text {off }}=30 \mu \mathrm{s} ; \mathrm{I}_{p}=6 \mathrm{~A}$
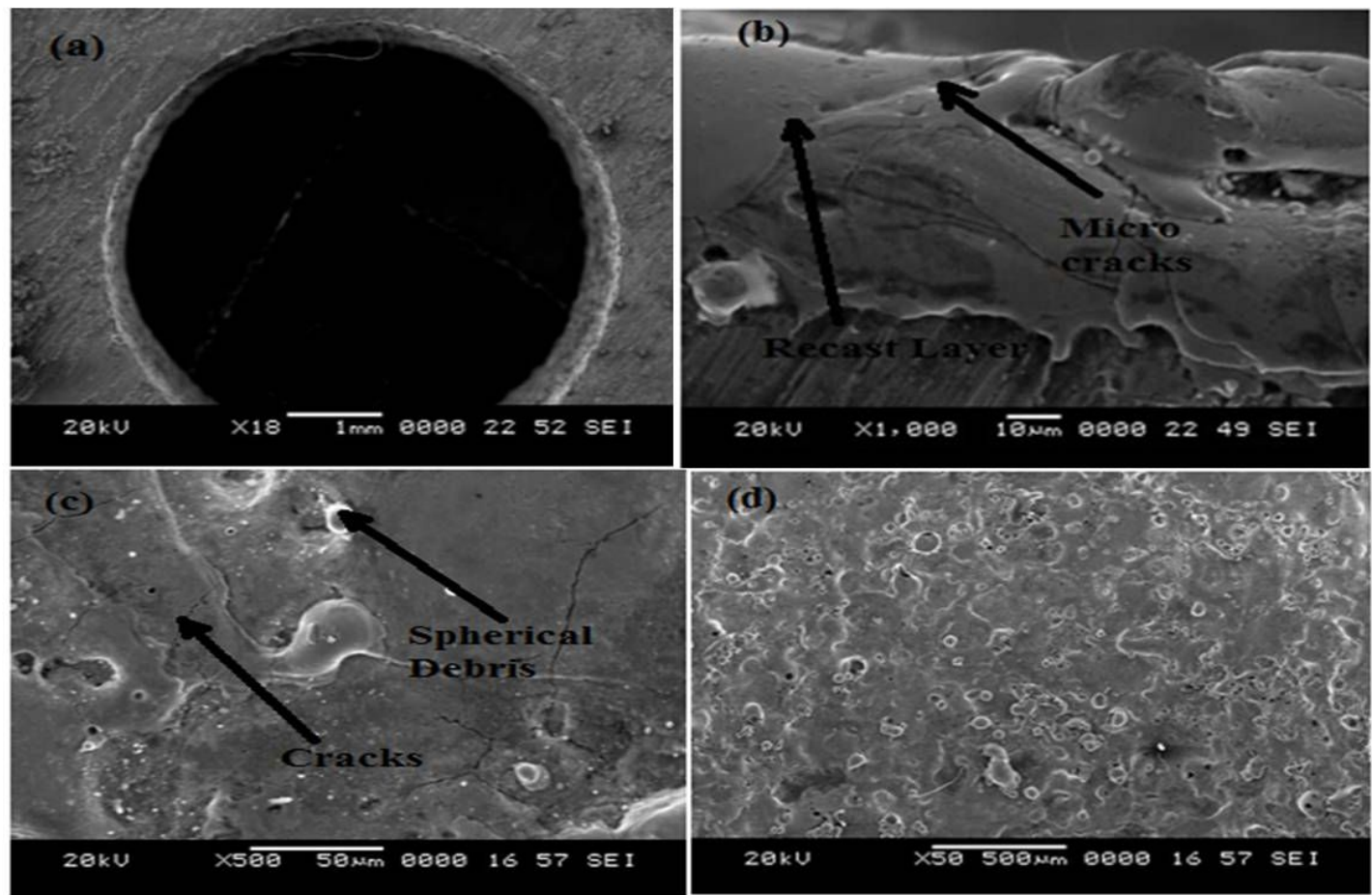

Figure 10: SEM micrograph: Exp No. 8 at $\mathrm{T}_{o n}=30 \mu \mathrm{s} ; \mathrm{T}_{\text {off }}=30 \mu \mathrm{s} ; \mathrm{I}_{p}=9 \mathrm{~A}$ 


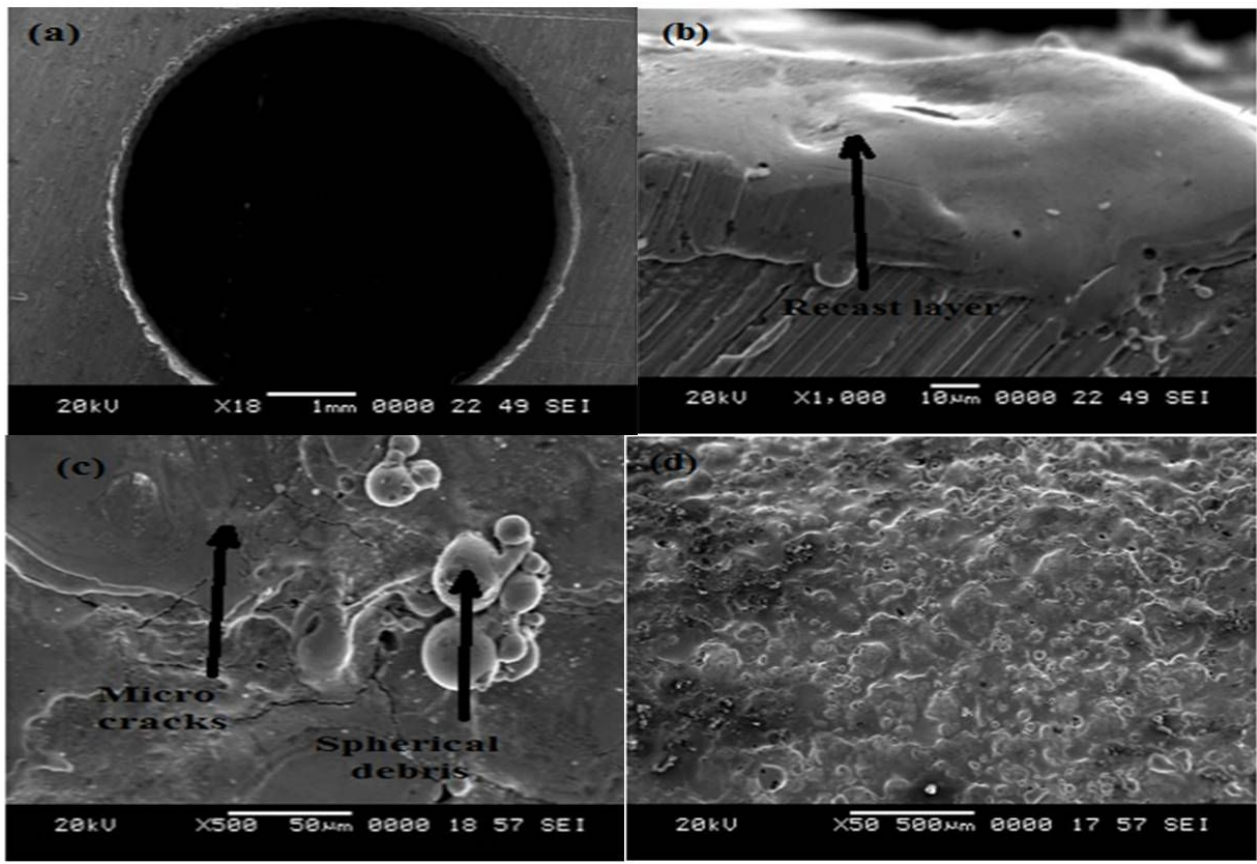

Figure 11: SEM micrograph: Exp No. 15 at $\mathrm{T}_{\text {on }}=30 \mu \mathrm{s} ; \mathrm{T}_{\text {off }}=50 \mu \mathrm{s} ; \mathrm{I}_{p}=2 \mathrm{~A}$
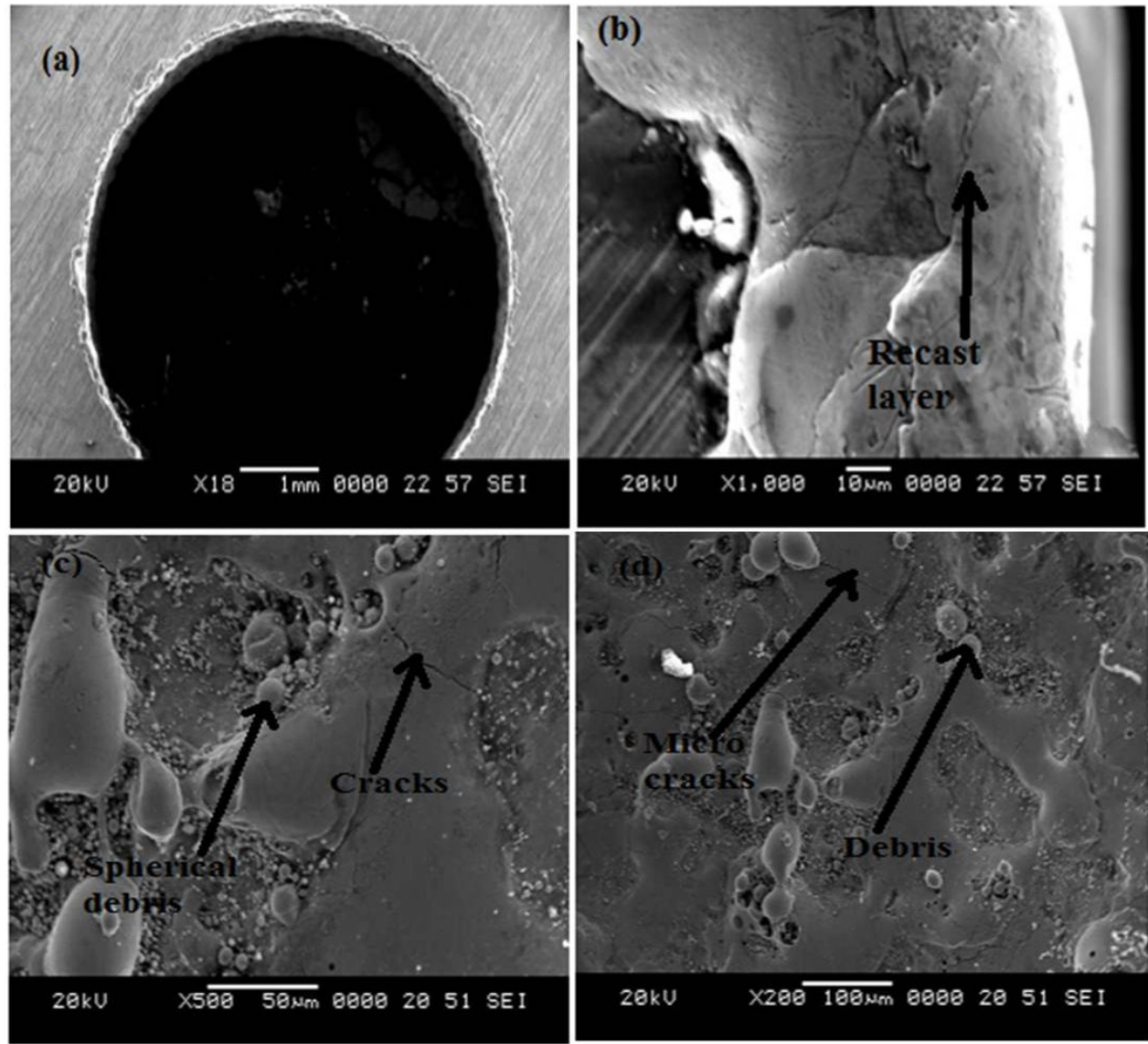

Figure 12: SEM micrograph: Exp No. 1; at $\mathrm{T}_{o n}=30 \mu \mathrm{s} ; \mathrm{T}_{\text {off }}=30 \mu \mathrm{s} ; \mathrm{I}_{p}=6 \mathrm{~A}$ 


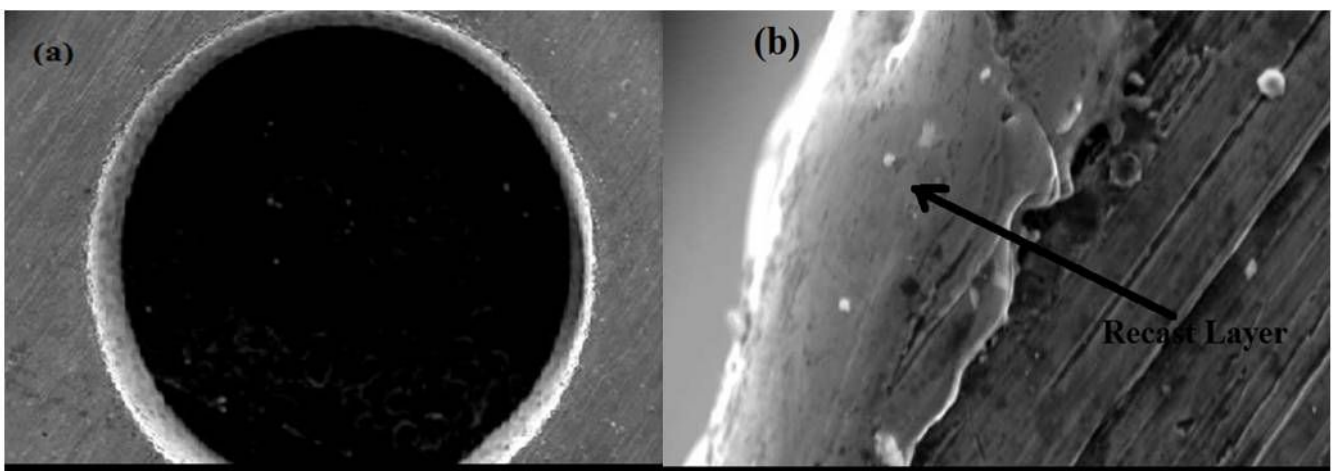

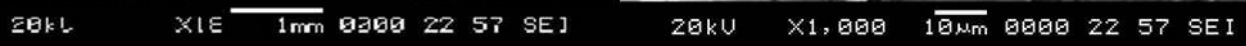

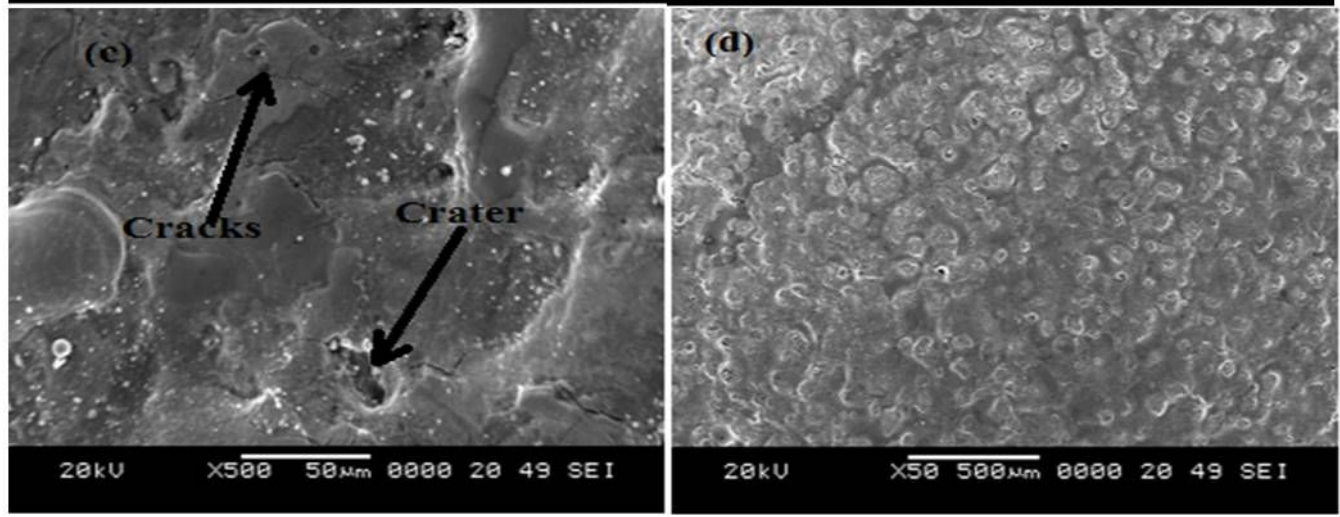

Figure 13: SEM micrograph: Exp No. 5; at $\mathrm{T}_{\text {on }}=10 \mu \mathrm{s} ; \mathrm{T}_{\text {off }}=30 \mu \mathrm{s} ; \mathrm{Ip}=2 \mathrm{~A}$

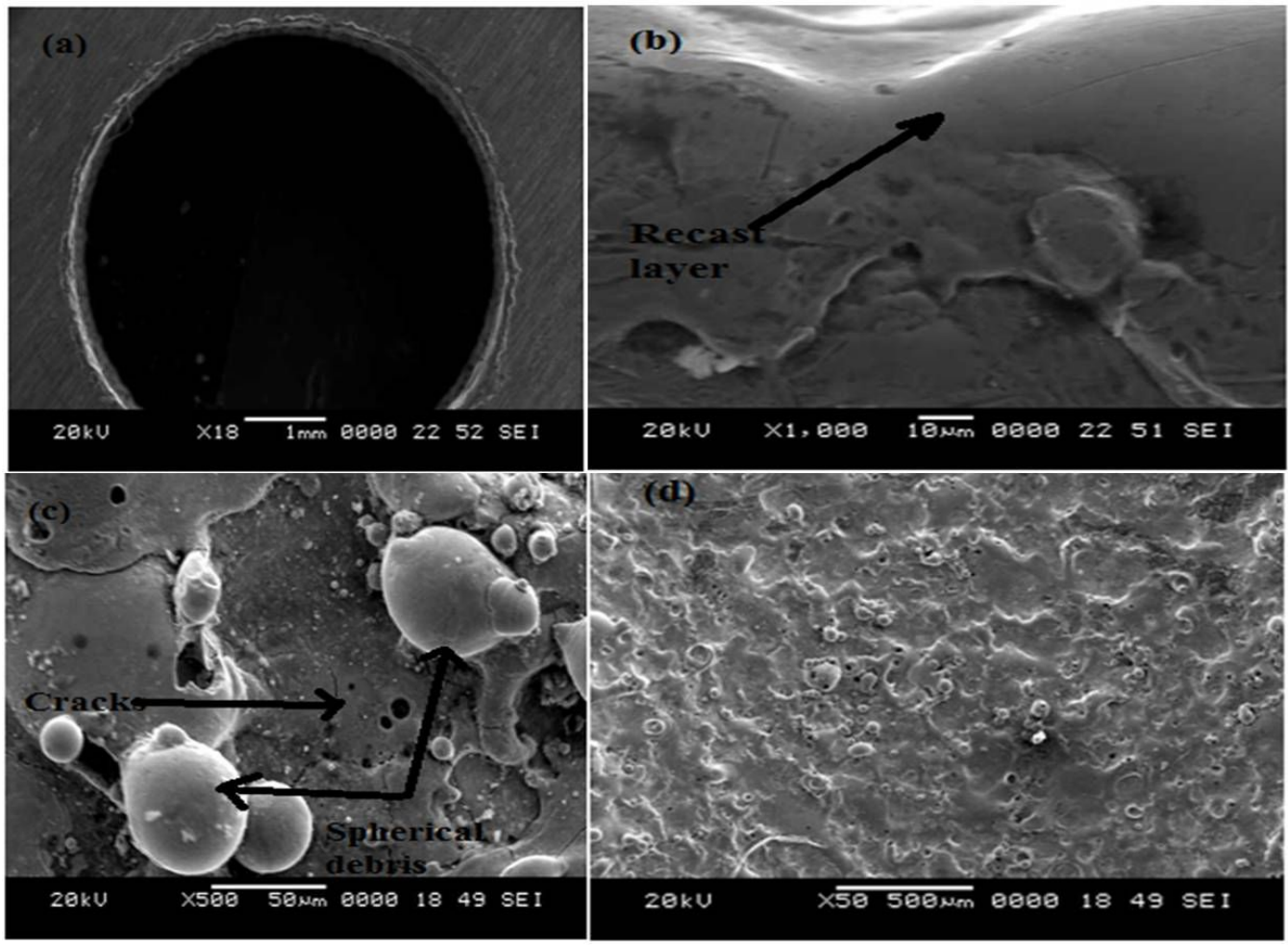

Figure 14: SEM micrograph of optimal setting at $\mathrm{T}_{o n}=10 \mu \mathrm{s} ; \mathrm{T}_{\text {off }}=10 \mu \mathrm{s} ; \mathrm{I}_{p}=4 \mathrm{~A}$ 

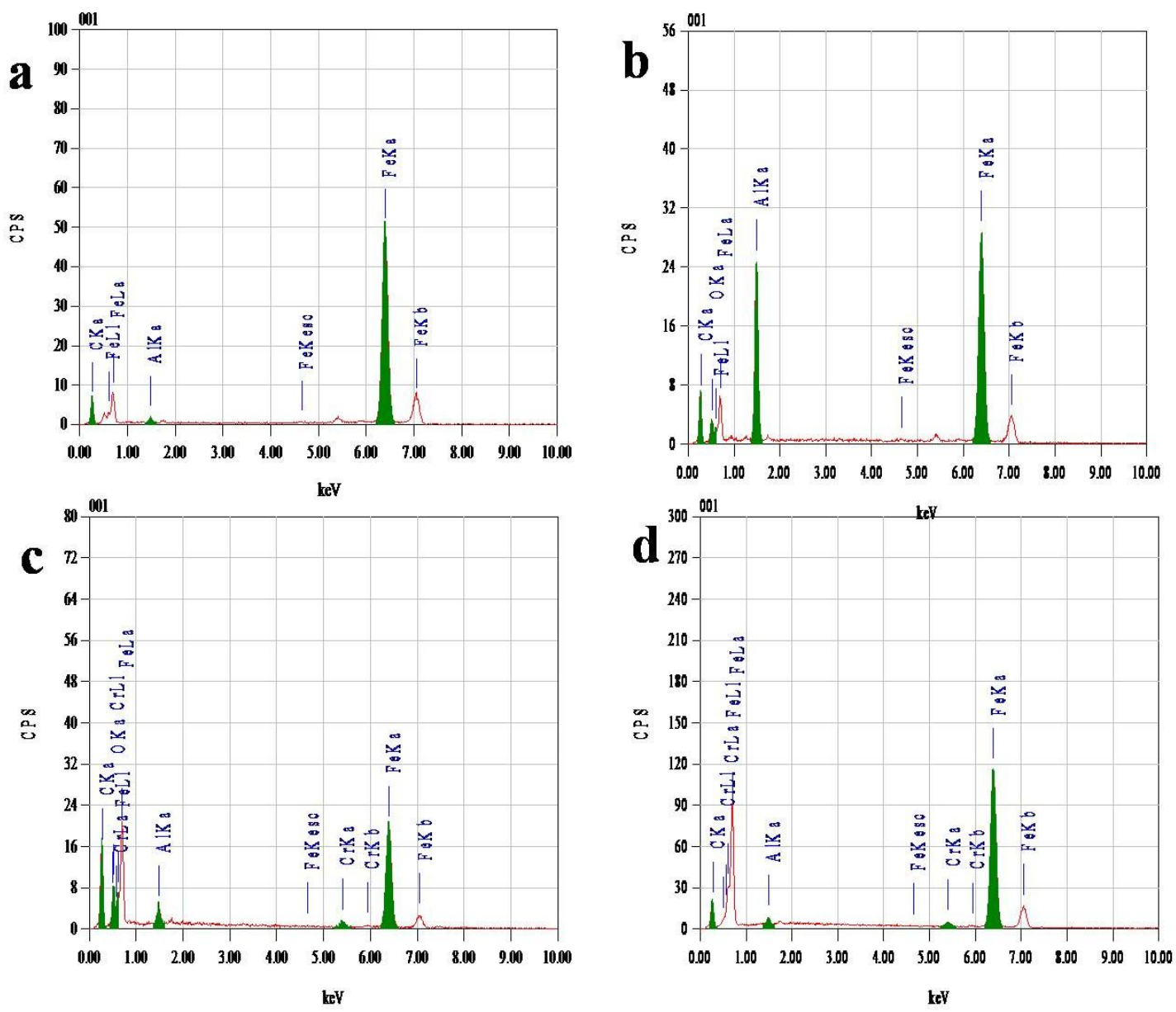

Figure 15: Energy dispersive X-ray analysis (EDX) of machined hole

\section{Surface morphology}

The effect of process parameters on EN-31 can be clearly observed from SEM micrographs as shown in Figures 9-13. Every spark discharge energy, the machined surface observed with craters as shown in Figures 9d-13d. The surface topography was altered due to significant effect of Ton, Toff and Ip [30-35]. When Ton was increased, the surface texture of the machined surface is composed of varying sizes of deep craters, melt re-solidifies to form lumps of spherical debris as observed in micrographs. The micrographs from Figure $9 \mathrm{~b}-13 \mathrm{~b}$ observed with formation of recast layer at the cross section of the hole. The thickness of recast layer by stationary electrode was observed more. It was also observed the micro-cracks on the surface and the recast layer. Energy Dispersive X-ray (EDX) composition analysis was carried on the side of the hole surface. The EDX plots shows the peaks of different elements were shown in Figure 15a-15d. The tool and work material particles were transfer and deposited on the side of hole surface

in compound or free form as shown in Table 7. The peaks of carbon, $\mathrm{O}_{2}, \mathrm{Al}, \mathrm{Cr}$ and $\mathrm{Fe}$ were confirmed the migrate elements on the surface of the work and tool. The presence of carbon on the work material is as a result of decomposition of hydrocarbon of kerosene oil used as dielectric and alloying elements of EN31.

\section{Multi-response optimization through desirability function}

For single and multiple quality characteristics problems in the industries the desirability function was most widely used. For numerical multi response optimization design expert 7.0 software was used to analyze the output each response respectively. The individual desirability index (di) for each response was calculated and the combined to calculate the composite desirability (D) [31, 32].

$$
D G=\left(d_{1}^{w 1} \times d_{2}^{w 2} \times \ldots \ldots d_{n}^{w n}\right.
$$



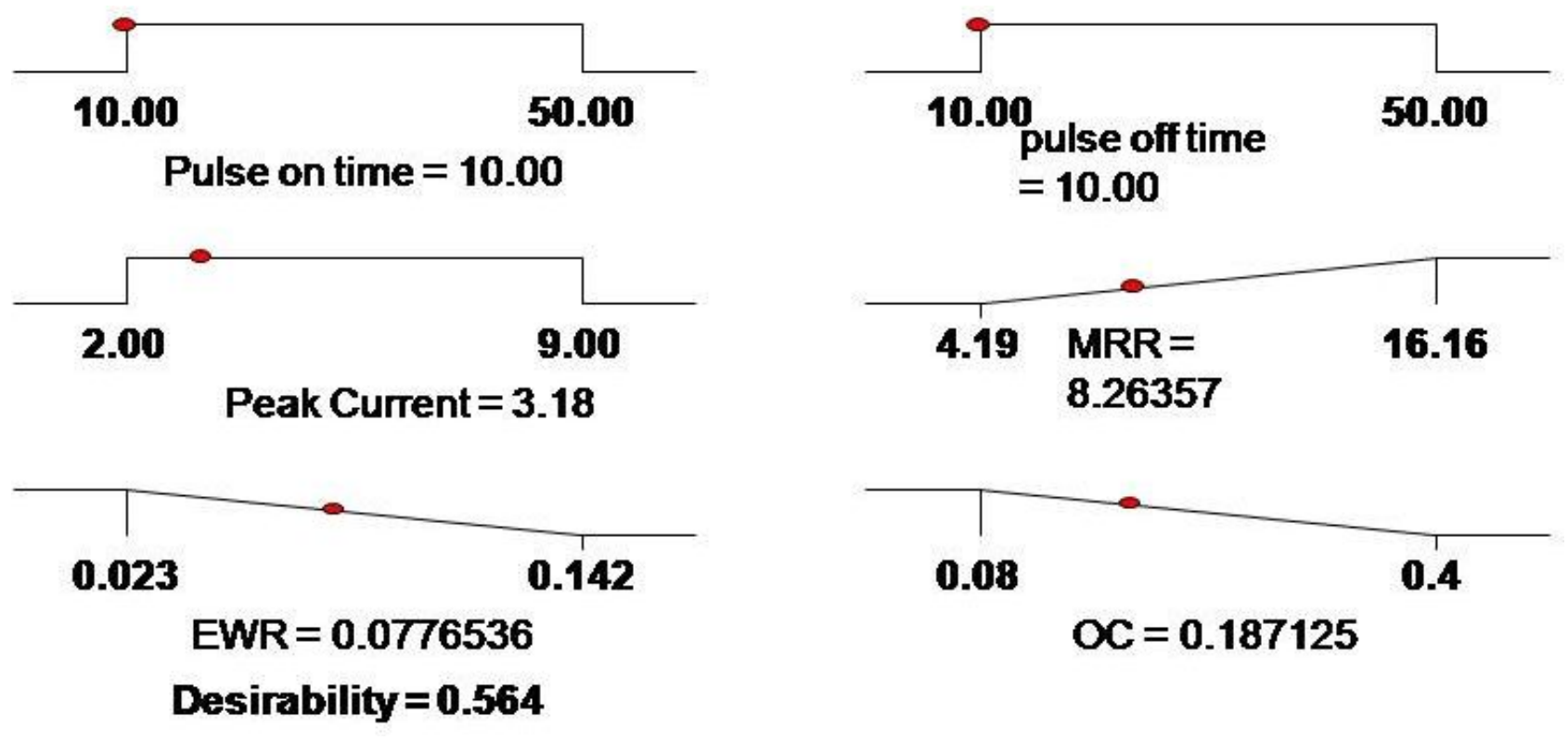

Figure 16: Ramp Graph showing desirability for MRR; EWR and Overcut

Table 9: Validation of Mathematical models with experimental data

\begin{tabular}{cccccccccc}
\hline Exp. No. & \multicolumn{3}{c}{ Experimental results } & \multicolumn{3}{c}{ RSM model prediction } & \multicolumn{3}{c}{ Prediction error(\%) } \\
& MRR & EWR & OC & MRR & EWR & OC & MRR & EWR & OC \\
\hline 1. & 8.50 & 0.080 & 0.190 & 8.26 & 0.077 & 0.187 & 2.8 & 3.7 & 1.5 \\
2. & 8.20 & 0.070 & 0.180 & 8.00 & 0.074 & 0.174 & 2.4 & 2.6 & 3.3 \\
\hline
\end{tabular}

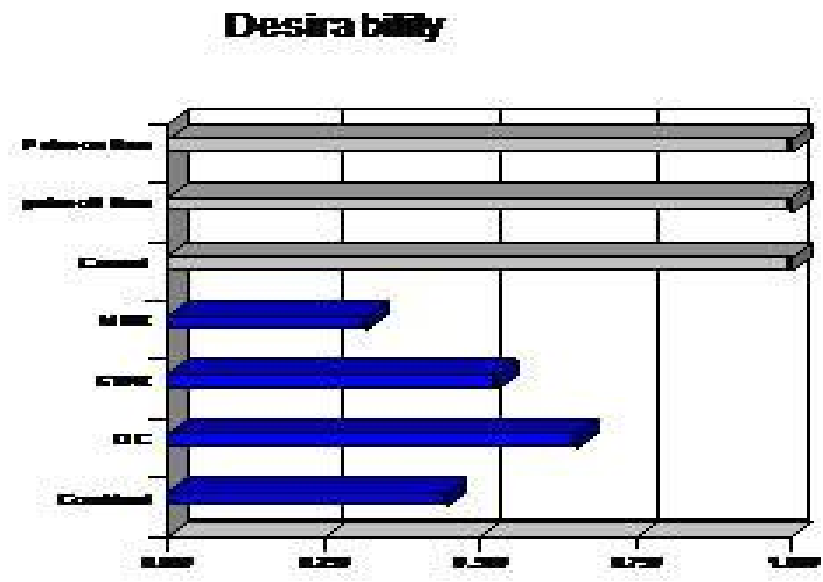

Figure 17: Bar Graph showing desirability for MRR; EWR and Overcut

Table 8 shows the composite desirability and the corresponding values of predicted responses obtained are also given. The current optimal process parameter settings are Ton of $10 \mu \mathrm{s}$, Toff of $10 \mu \mathrm{s}$, Ip of $4 \mathrm{~A}$ and Figure 14 of SEM micrographs was observed with less number of cracks and craters. The three responses MRR, EWR and OC are shown in Figures 16-18 with contour plots and optimized histograms.

\section{Validation of experimental results}

Prediction error in Table 9 has been calculated by the following formula.

Prediction error

$$
=\frac{\text { Experimental Result }- \text { Predicated Result }}{\text { Experimental Result }} \times 100
$$

In order to validate the developed models the confirmatory experiment was carried out and the obtained results are i.e. $\mathrm{MRR}=8.50 \mathrm{~mm}^{3} / \mathrm{min}, \mathrm{EWR}=0.077 \mathrm{~mm}^{3} / \mathrm{min}$ and $\mathrm{OC}=0.190$ $\mathrm{mm}$, respectively. Table 9 shows the error percentage between experimental and predicted values for MRR, EWR and $\mathrm{OC}$ lies within $2.8 \%, 3.7 \%$ and $1.5 \%$, respectively. 


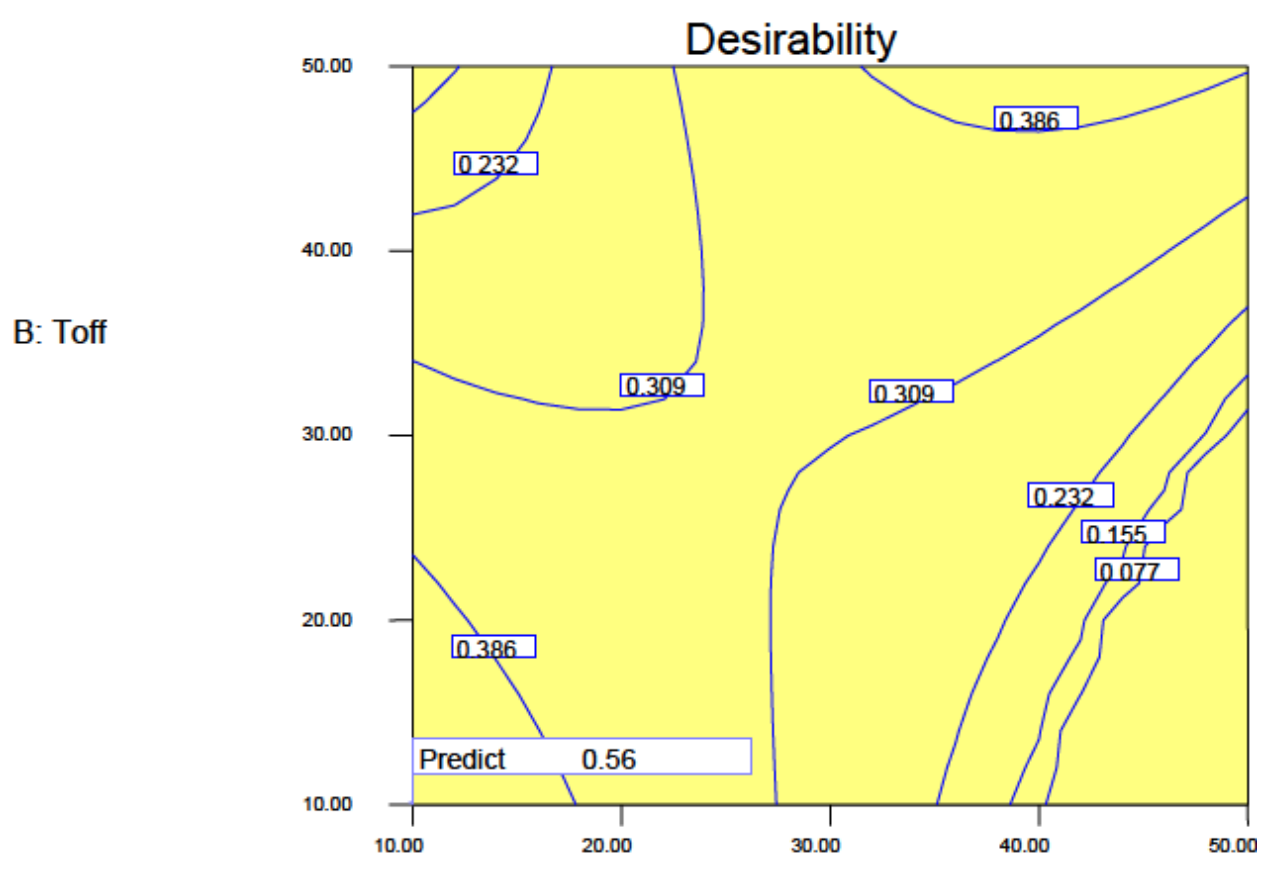

A: Ton

Figure 18: Graph between Ton and Toff for desirability

\section{Conclusion}

In this study, the influence of process parameters on MRR, EWR and OC while drilling of EN31 by MFAEDM technique have been examined. From the experimental investigations, the following conclusions were drawn:

1. MRR increasing from $1.73 \mathrm{~mm}^{3} / \mathrm{min}$ to $16.14 \mathrm{~mm}^{3}$ /min with simultaneous increase of Ip and Ton The magnetic field produces significant effect on MRR at high Ton and Ip. The debris was driven off quickly and reduces the abnormal discharge.

2. EWR varies from $0.015 \mathrm{~mm}^{3} / \mathrm{min}$ to $0.26 \mathrm{~mm}^{3} / \mathrm{min}$ with the increase Ton by $10 \mu$ s to $50 \mu$ s with parallel decrease of Toff by 50 to $10 \mu$ s.The minimum EWR $0.012 \mathrm{~mm}^{3} / \mathrm{min}$ was obtained when the parameters were set at Ton is $10 \mu \mathrm{s}$, Toff is $30 \mu \mathrm{s}$ and Ip is $2 \mathrm{~A}$ with magnetic field.

3. It was observed that drilled hole has lower overcut with value of $0.11 \mathrm{~mm}$ at lower Ip $2 \mathrm{~A}$.

4. The optimized value of MRR, EWR and OC are 8.26 $\mathrm{mm}^{3} / \mathrm{min}, 0.077 \mathrm{~mm}^{3} / \mathrm{min}$ and $0.187 \mathrm{~mm}$ with desirability 0.563 was obtained. The optimal setting of parameters at Ton, Toff and Ip are $10 \mu \mathrm{s}, 10 \mu$ s and 3.18A respectively with magnetic field of $0.3 \mathrm{~T}$.
5. The confirmation tests showed that the error between experimental and predicted values of MRR, EWR and OC are $2.8 \%$ and 3.7\%, 1.5\% respectively.

6. The drilled hole surface with high Ton, Ip and low Toff observed with craters, micro-cracks, spherical deposits and recast layer. The material migration also observed through EDX showing with copper and work material elements.

\section{References}

[1] Bhattacharya A, Batish A, Bhatt G. Material transfer mechanism during magnetic field-assisted electric discharge machining of AISI D2, D3 and H13 die steel. Proc Inst Mech Eng B J Eng Manuf. 2015;229(1):62-74.

[2] Singh S, Maheshwari S, Pandey PC. Some investigations into electric discharge machining of hardened tool steel using different electrode materials. J Mat Proc Techn. 2015;149(1-3):272-7.

[3] Makenzi M, Bernard I, Nyakoe G. A study on the influence of $\mathrm{Nd}$-magnets on EDM surface quality of mild steel. Ind Eng Lett. 2013;3(2):42-51.

[4] Yan BH, Chang GW, Chang JH, Hsu RT. Improving electrical discharge machined surfaces using magnetic abrasive finishing. Mach Sci Techn. 2004;8(1):103-18.

[5] Singh S, Shan HS. Development of magneto abrasive flow machining process. Int J Mach Tools Manuf. 2002;42(8):953-9. 
[6] Cetin S, Okada A, Uno Y. Effect of debris accumulation on machining speed in EDM. Intl J Electr Mach. 2004;9:9-14.

[7] Kremer D, Lhiaubet C, Moisan A. A study of the effect of synchronizing ultrasonic vibrations with pulse in EDM. Ann. CIRP. 1991;40(1):211-4.

[8] Lin YC, Yan BH, Chang YS. Machining characteristics of titanium alloy (Ti-6Al-4V) using combination process of EDM with USM. J Mat Proc Techn. 2000;115(3):359-66.

[9] Lin YC, Lee HS. Optimization of machining parameters using magnetic-force-assisted EDM based on gray relational analysis. Int J Adv Manuf Techn. 2009;42(11-12):1052-64.

[10] Cao M, Wang Y, Yang S, Li W. Experimental and mechanism research on EDM combined with magnetic field. Key Eng Mat. 2009;416:337-41.

[11] Bhattacharya A, Batish A, Bhatt G. Mechanism of material deposition from powder, electrode and dielectric for surface modification of H11 and H13 die steels in EDM process. Mat Sci Forum. 2012;701:61-75.

[12] Joshi S, Govindan P, Malshe A, Rajurkar K. Experimental characterization of dry EDM performed in a pulsating magnetic field, Ann. CIRP. Manuf. Techn. 2011;60(1):239-42.

[13] Chattopadhyay KD, Satsangi PS, Verma S, Sharma PC. Analysis of rotary electrical discharge machining characteristics in reversal magnetic field for copper-EN8 steel system. Int J Adv Manuf Techn. 2008;38(9-10):925-37.

[14] Wang Y, Hu D. Study on the inner surface finishing of tubing by magnetic abrasive finishing. Int J Mach Tools Manuf. 2005;45(1):43-9.

[15] Wang X, Liu Z, Xue R, Tian Z, Huang Y. Research on the influence of dielectric characteristics on the EDM of titanium alloy. Int J Adv Manuf Techn. 2014;72(5-8):979-87.

[16] Teimouri R, Baseri H. Study of tool wear and overcut in EDM process with rotary tool and magnetic field. Adv. Tribo. 2012;35(8):18.

[17] Payal HS, Choudhary R, Singh S. Analysis of electro discharge machined surfaces of EN-31 tool steel. J Sci Ind Res (India). 2013;67:1072-7.

[18] Kumar A, Kumar V, Kumar J. Investigation of machining parameters and surface integrity in wire electric discharge machining of pure titanium. Proc Inst Mech Eng B J Eng Manuf. 2013;227(7):972-92.

[19] Kumar A, Kumar V, Kumar J. Investigation of microstructure and element migration for rough cut surface of pure titanium after WEDM. Int J Micro Mat Proper. 2013;8(4/5):343-56.

[20] Lin YC, Chen YF, Wang DA, Lee HS. Optimization of machining parameters in magnetic force assisted EDM based on Taguchi method. J Mat Proc Techn. 2009;209(7):3374-83.
[21] Peruri SR, Chaganti PK. A review of magnetic-assisted machining processes. J Braz Soc Mech Sci Eng. 2019;41(10):450.

[22] Prabhu S, Uma M, Vinayagam BK. Electrical discharge machining parameters optimization using response surface methodology and fuzzy logic modeling. J Braz Soc Mech Sci Eng. 2014;36(3):637-52.

[23] Kumar A, Kumar V, Kumar J. Semi-empirical model on MRR and Overcut evaluation in WEDM process of pure titanium using a Derringer's Desirability Function. J Braz Soc Mech Sci Eng. 2015;37(2):689-721.

[24] Montgomery DC. Design and analysis of experiments. Wi-ley New York; 1997.

[25] Dikshit KM, Anand J, Narayan D, Jinda S. Machining characteristics and optimization of process parameters in die-sinking EDM of Inconel 625. J Braz Soc Mech Sci Eng. 2019;41(7):302.

[26] Vikas S, Kumar V. Multi-objective optimization of laser cutting of aluminium metal matrix composites using desirability approach. J Braz Soc Mech Sci Eng. 2016;38(4):1221-38.

[27] Bains SP, Sidhu SS, Payal HS. Magnetic field assisted EDM, New horizons for improved surface properties. Silicon. 2018;10(4):1275-82.

[28] Kansal HK, Singh S, Kumar P. Effect of silicon powder mixed EDM on machining rate of AISI D2 die steel. J Manuf Proc. 2007;9(1):1321.

[29] Pradhan BB, Masanta M, Sarkar BR, Bhattacharyya B. Investigation of electro-discharge micro-machining of titanium super alloy. Int J Adv Manuf Techn. 2009;41(11-12):1094-106.

[30] Iqbal Asif AK, Khan AA. Influence of process parameters on electrical discharged machined job surface integrity. Am J Eng Appl Sci. 2010;3(2):396-402.

[31] Kumar A, Garg MP, Sahu CK. Mathematical modeling and analysis of WEDM machining parameters of nickel based super alloy using response surface methodology. Sadh. 2017;42(6):981-1005.

[32] Kumar P, Gupta M, Kumar V. Microstructural analysis and multi response optimization of WEDM of Inconel 825 using RSM based desirability approach. J Mech Behav Mater. 2019;28(1):39-61.

[33] Rouniyar KA, Shandilya P. Fabrication and experimental investigation of magnetic field assisted powder mixed electrical discharge machining on machining of aluminum 6061 alloy. Proc Inst Mech Eng, B J Eng Manuf. 2019;223(12):2283-91.

[34] Bhatt G, Batish A, Bhattacharya A. Experimental investigation of magnetic field assisted powder mixed electric discharge machining. Particul Sci Technol. 2015;33(3):246-56.

[35] Gohil V, Puri YM. Statistical analysis of material removal rate and surface roughness in electrical discharge turning of titanium alloy (Ti-6Al-4V), Proc. I Mech., Part B, J. Eng. Manuf. 2018;232(9):1603-14. 